J. Amer. Soc. Hort. Sci. 115(6):991-999. 1990.

\title{
Endogenous Abscisic Acid Concentrations, Vegetative Growth, and Water Relations of Apple Seedlings following PEG-induced Water Stress
}

\author{
Terence L. Robinson'and Bruce H. Barritt \\ Washington State University, Tree Fruit Research Center, Wenatchee, WA 98801
}

Additional index words. Malus domestica, polyethylene glycol, bound ABA, plastochron index, leaf expansion rate, leaf water potential, osmotic potential, turgor potential

\begin{abstract}
In unstressed apple seedlings (Malus domestics Borkh.), concentrations of free abscisic acid (ABA) decreased in order from apical stem sections, immature expanding leaves, mature stem sections, and mature leaves. PEG-induced water stress stimulated a 2- to 10-fold increase in free ABA concentrations 1 day after treatment, depending on the amount of stress and the tissue. By the 3rd day of stress, free ABA concentrations were nearly the same as the unstressed treatment and remained low for the remainder of the 21-day stress period. Bound ABA concentrations were an order of magnitude lower than free ABA and were not influenced dramatically by water stress. Shoot growth rate, leaf expansion rate, and leaf emergence rate were reduced by water stress in relation to the severity of the stress; this reduction was associated with the initial increase in ABA. However, there was no increase in shoot or leaf growth rates associated with the decline in ABA concentrations by day 3 as growth rates remained depressed on water-stressed plants throughout the 21-day stress period. Water stress reduced evapotranspiration rate and midshoot leaf water potential $\left(\psi_{w}\right)$ after 1 day, but leaf osmotic potential $\left(\psi_{s}\right)$ adjusted more slowly, resulting in a loss of leaf turgor. The reduction in leaf turgor pressure $\left(\psi_{\mathrm{p}}\right)$ was highly correlated with decreased shoot growth rate and increased ABA concentrations on day 1 after treatment. By the 3rd day of water stress, $\psi_{p}$ bad recovered even in the most severe treatment, and the recovery of turgor was associated with the drop in $A B A$ concentrations. However, the increase in midshoot $\psi_{\mathrm{p}}$ and the decline in ABA were not associated with any increase in shoot growth rate. The continued inhibition of shoot growth was probably not related to ABA or turgor pressure of mature leaves but may have been related to turgor pressure in the growing tip.
\end{abstract}

Shoot extension growth depends on a positive cell turgor pressure as a driving force and enzymatic cell wall synthesis (Hsiao, 1973). The rate of shoot growth is also thought to be influenced by the internal hormonal balance of growth promoters and growth inhibitors (Avery et al., 1937; Looney et al., 1988; Luckvvill and Whyte, 1968; Sandke, 1982; Seeley and Powell, 1981). The hormonal balance is readily perturbed by environmental stimuli (Little and Wareing, 1981) and, as such, varies seasonally-. The concentrations of growth promoters (auxins, cytokinins, and gibberellins) increase before bloom, then decrease as shoot growth stops, and remain low throughout the fall and winter (Avery et al., 1937; Luckwill and Whyte, 1968). The concentration of the growth inhibitor abscisic acid (ABA) increases throughout the summer to a maximum in early winter, then decreases to a minimum near full bloom (Seeley and Powell, 1981).

ABA is a potent inhibitor of growth when applied exogenously, and it also causes stomatal closure (Bingham, 1972, Powell, 1975; Walton, 1980). Water stress has been shown to cause a rapid accumulation of ABA in many plants, including apple (Bingham, 1972; Walton, 1980; Wright, 1978). The rapid accumulation of $\mathrm{ABA}$ has been shown to result from de novo synthesis rather than a release from a bound form of $\mathrm{ABA}$ in red kidney bean and scotch pine (Hogue et al., 1983; Pierce and Raschke, 1981). The endogenous increase in ABA due to water stress is presumed to cause the closure of stomates and

Received for publication 24 July 1989. H/LA paper no. 89-12. College of Agriculture and Home Economics Research Center, Washington State Univ., Pullman. We thank the Washington State Tree Fruit Research Commission for supporting this research. The cost of publishing this paper was defrayed in part by the payment of page charges. Under postal regulations, this paper therefore must be hereby marked advertisement solely to indicate this fact.

'Present address: Dept. of Horticultural Sciences, New York State Agricultural Experiment Station, Cornell University, Geneva, NY 14456. possibly an inhibition of growth (Wright, 1978). Upon dehydration of the plant, the $\mathrm{ABA}$ content returns to the unstressed level. In apple, the increase in ABA of mature leaves is correlated with cell turgor pressure rather than water potential (Davies and Lakso, 1978). Mature leaves can maintain a positive cell turgor through active and passive osmotic adjustment despite increasing water stress (Lakso, 1983). The accumulation of ABA in response to water stress has been measured in mature leaves (Bingham, 1972; Davies and Lakso, 1978), yet the young leaves and the shoot tip where growth occurs have been shown to lack the ability to osmotically adjust (Lakso, 1983).

The objectives of this study were to: 1) determine the effect of water stress on the accumulation of free and bound ABA in the growing regions and in the mature section of the shoot of apple; and 2) answer the question: Are the changes in ABA concentration correlated with changes in growth rate during an osmotically induced water stress?

\section{Materials and Methods}

Plant material. Open-pollinated 'Golden Delicious' apple seeds were stratified in the dark for $1200 \mathrm{hr}$ at $5 \mathrm{C}$ and then grown in sterile vermiculite in a controlled environment of $27 \mathrm{C}, 50 \% \mathrm{RH}$, and a 16-hr photoperiod with a radiant flux density of $115 \mathrm{~W} \cdot \mathrm{m}$ $(400$ to $700 \mathrm{~nm})$ at plant apex provided by cool-white fluorescent and incandescent lighting. The light bank was adjusted weekly to maintain a constant distance to plant apex. Seedlings were subirrigated and provided with $50 \mathrm{ml}$ of half-strength nutrient solution once weekly (Hoagland and Arnon, 1950).

Thirty-one days after planting, seedlings with an average height of $160 \pm 30 \mathrm{~mm}$ were transferred to 0.94-liter aluminum foil-

Abbreviations: ABA, abscisic acid; c, t-ABA, cis, trans-abscisic acid; LPI, leaf plastochron index; PI, plastochron index age; $\psi_{\mathrm{p}}$, leaf turgor pressure; $\psi_{\mathrm{s}}$, leaf osmotic potential; $\psi_{\boldsymbol{w}}$ : leaf water potential; $t$, t-ABA, trans, trans-abscisic acid. 
covered glass jars filled with nutrient solution in a manner similar to Gergeley et al. (1980). The nutrient solution consisted of the following (in mmol.liter ${ }^{-1}$ ): $1 \mathrm{NH}_{4} \mathrm{H}_{2} \mathrm{PO}_{4} ; 6 \mathrm{KNO}_{3} ; 4$ $\mathrm{Ca}\left(\mathrm{NO}_{3}\right)_{2} ; 2 \mathrm{MgSO}_{4}$; and (in $\mu \mathrm{mol} \cdot$ liter $^{-1}$ ) $46.3 \mathrm{H}_{3} \mathrm{~B} \mathrm{O}_{3} ; 9.2$ $\mathrm{MnC}_{2} \cdot 4 \mathrm{H}_{2} \mathrm{O} ; 0.76 \mathrm{ZnSO}_{4} \cdot 7 \mathrm{H}_{2} \mathrm{O} ; 0.32 \mathrm{CuSO}_{4} \cdot 5 \mathrm{H}_{2} \mathrm{O} ; 0.11$ $\mathrm{H}_{2} \mathrm{MoO}_{4} \cdot \mathrm{H}_{2} \mathrm{O} ; 89.4 \mathrm{NaFeEDTA}$ (Hoagland and Arnon, 1950). Nutrient solutions were changed once weekly and were aerated continuously at a rate of $3.3 \mathrm{ml} \cdot \mathrm{s}^{-1}$. Water loss from the bottles was replaced daily by volumetric additions, and total water use was determined twice weekly by weighing the jars and calculating water losses and additions (Gergeley et al., 1980). Water use was corrected for water loss from an aerated jar with no plants and then used to calculate evapotranspiration.

Plant growth was measured twice weekly. Shoot length was measured from the cotyledonary node to the youngest visible node. The plastochron index age (PI) of each plant was determined according to Maksymowych (1973), with a leaf reference length of $10 \mathrm{~mm}$. The area of a leaf on each plant between leaf plastochron index (LPI) 1 and 3 was measured at each observation date with a LI-COR (LI-COR, Lincoln, Neb.) portable leaf area meter and the same leaf was measured at the next observation date. Shoot growth rate, new leaf emergence rate, and leaf expansion rate were calculated from the change over time in shoot length, PI, and leaf area, respectively.

Water stress. After a 20-day acclimation period in the growth chamber, seedlings with an average shoot length of $381 \mathrm{~mm}$ and average PI of 27 were subjected to an osmotically induced water stress created by the addition of PEG 8000 (polyethylene glycol, molecular weight 7000 to 9000) to the nutrient solution. The following solution water potentials were used $\left(\psi_{\mathrm{PEG}}\right)[\mathrm{g}$ PEG/liter]; - 0.5 MPa [169.0], and - 1.0 MPa [265.0]. Water potential of the solution was measured psychometrically with a Wescor C-52 (Wescor, Logan, Utah) sample chamber psychrometer calibrated, against $\mathrm{NaCl}$ solutions of known $\psi$ (Steuter et al., 1981). Control plants received only nutrient solution $(-0.07$ $\mathrm{MPa})$.

ABA sample collection. Twelve replicates of each treatment were destructively sampled at $-5,0,1,3,7,14$, and 21 days after water stress treatment for analysis of endogenous cis, transabscisic acid (c, t-ABA). Four tissue types were sampled: 1) the actively elongating apical stem section, including the apical meristem down to and including LPI node $4 ; 2$ ) the associated actively expanding leaves of LPI -1 to 4 ; 3) a mature stem section below LPI node 8 down to and including LPI node 12; and 4) the associated mature leaves of LPI 9 to 12 . These sections of the plant were chosen based on measurements of internode elongation and leaf expansion rates over 2 days that showed active internode elongation was restricted to the internodes above the node of LPI 5 (Fig. 1A), while active leaf expansion occurred in leaves younger than LPI 9 (Fig. 1B). Samples were collected during the $3 \mathrm{hr}$ following the midpoint of the photoperiod on each sampling date. Harvested tissue samples were immediately frozen in liquid $\mathrm{N}$, lyophilized, and stored at - 30C in a vacuum desiccator until analyzed.

$A B A$ extraction and fractionation. Treatment replicates were bulked by chamber resulting in two replicates of six plants each for each sampling date. The lyophilized samples were ground to pass a 20-mesh sieve and up to $1 \mathrm{~g}$ (dry weight) was weighed for ABA analysis. The samples of apical stem sections contained on the average only $360 \mathrm{mg}$ of total tissue while the other tissue samples exceeded $1 \mathrm{~g}$. Samples were extracted for $24 \mathrm{hr}$ at $4 \mathrm{C}$ in the dark with $20 \mathrm{ml}$ of 80 methanol : 20 water : 1 acetic acid (by volume) with $100 \mathrm{mg}$ butylated hydroxytoluene

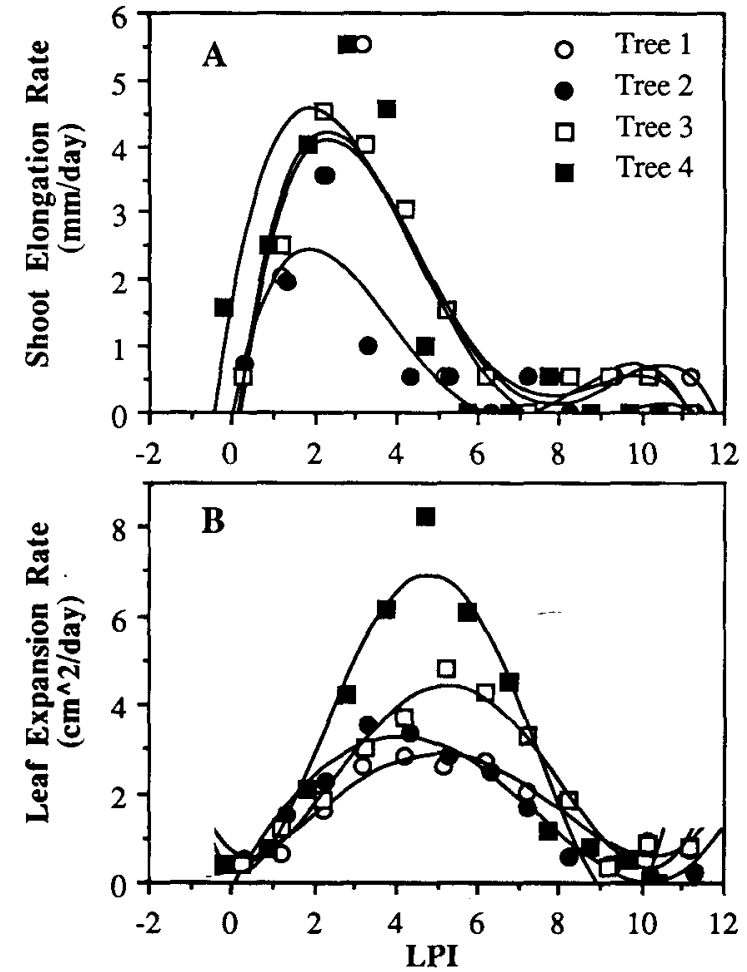

Fig. 1. Distribution along a shoot of internode elongation rate $(A)$ and leaf expansion rate (B) for four apple seedlings. Rate calculated from increase in internode length and leaf area over 2 days in ABA experiment. Highly significant quartic regression curves calculated for each tree.

(BHT)/liter added as an antioxidant. Immediately upon the addition of the extractant, 250 or $500 \mathrm{ng}$ of trans, trans-ABA $(t, t$ ABA) was added to the sample as an internal standard (Lenton et al., 1971; Saunders, 1978; Wood, 1983). Following extraction, the samples were centrifuged and reextracted for $1 \mathrm{hr}$ with $10 \mathrm{ml}$ of the same extractant; filtered through Whatman no. 1 filter paper; evaporated in vacuo at $35 \mathrm{C}$ to the aqueous phase; diluted to $25 \mathrm{ml}$ with $0.2 \mathrm{M}$ phosphate buffer $\left(\mathrm{K}_{2} \mathrm{HPO}_{4}\right) \mathrm{pH} 8$; adjusted to $\mathrm{pH} 8$ with $2 \mathrm{~N} \mathrm{NaOH}$; partitioned with hexane (2 $\mathrm{x}$ vol.) to remove nonpolar pigments; adjusted to $\mathrm{pH} 3$ with 2 $\mathrm{N} \mathrm{HC1}$; and partitioned with ethyl acetate ( $3 \times 1 / 2$ vol). The remaining aqueous phase was retained for bound $\mathrm{ABA}$. The acidic ethyl acetate phase was evaporated in vacuo at $35 \mathrm{C}$; dissolved in $1 \mathrm{ml}$ of methanol; applied to a $2.9-\mathrm{g}$ column $(10 \mathrm{x}$ $1.8 \mathrm{~cm}$ ) of undefined insoluble polyvinylpyrrolidone (prewashed with three volumes of methanol) and eluted with methanol (Mousdale and Knee, 1979). The 12- to 28-ml fraction containing $\mathrm{ABA}$ (elution range 17 to $23 \mathrm{ml}$ ) was reduced to dryness in vacuo at $35 \mathrm{C}$, dissolved in $500 \mu \mathrm{l}$ of methanol, diluted to $5 \mathrm{ml}$ with $0.01 \mathrm{M}$ phosphate buffer $\left(\mathrm{KH}_{2} \mathrm{PO}_{4},\right) \mathrm{pH} 2.8$, and loaded onto a small $(4.0 \times 0.8 \mathrm{~cm})$ open column of octadecylsilane (C-18) (700 mg) obtained from C-18 Sep-Paks (Waters Associates, Milford, Mass.). The columns were previously washed with acetone, methanol, and lastly $0.01 \mathrm{M}$ phosphate buffer $\mathrm{pH}$ 2.8. The sample was pumped through the column at a flow rate of 2 to $3 \mathrm{ml} \cdot \mathrm{min}^{-1}$, followed by a $10-\mathrm{ml}$ wash of

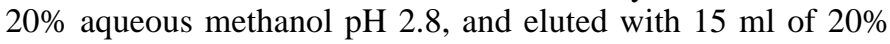
aqueous methanol pH 8.0 (Lewis and Visscher, 1982). This fraction was. acidified to $\mathrm{pH} 2.8$ with dilute $\mathrm{H}_{3} \mathrm{PO}_{4}$, pumped through a second $\mathrm{C}-18$ column, rinsed with $1 \mathrm{ml}$ of distilled $\mathrm{H}_{2} \mathrm{O}$ eluted in $3 \mathrm{ml}$ of methanol (freshly distilled over BHT), and evaporated in vacuo at $35 \mathrm{C}$. 
The above aqueous phase containing bound $\mathrm{ABA}$ was spiked with $250 \mathrm{ng}$ of $t$, t-ABA, adjusted to $\mathrm{pH} 10.5$ with $2 \mathrm{~N} \mathrm{NaOH}$, heated to 60C for $1 \mathrm{hr}$ (Wood, 1983), adjusted to pH $2.8(2 \mathrm{~N}$ $\mathrm{HC} 1)$, and partitioned with ethyl acetate $(3 \times 1 / 2$ vol. $)$. The organic fraction was evaporated in vacuo at $35 \mathrm{C}$ and the. residue chromatographed on a C-18 column as described above. Carryover $\mathrm{t}, \mathrm{t}-\mathrm{ABA}$ from the previous spiking was not estimated.

Gas-liquid chromatography (GLC). The purified bound and free ABA samples were each dissolved in $200 \mu \mathrm{l}$ of methanol, methylated with $1 \mathrm{ml}$ ethereal diazomethane for 10 min (Black, 1983), dried under $\mathrm{N}_{2}$, and redissolved in ethyl acetate (freshly distilled over BHT) before quantification. Quantification of c, tABA was done with a Packard 7400 series gas chromatography equipped with a ${ }^{63} \mathrm{Ni}$ electron capture detector, and using a 2 mm x $180 \mathrm{~cm}$ spiral glass column packed with 3\% Epon 10901 on Supelcoport (80/100 mesh) (Lenton et al., 1971). Nitrogen flow rate was $50 \mathrm{ml} \cdot \mathrm{min}^{-1}$ and injection, column, and detector temperatures were 220,210 , and $220 \mathrm{C}$, respectively. Retention times for $\mathrm{c}, \mathrm{t}-\mathrm{ABA}$ and $t, t-A B A$ were 15 and 21 rein, respectively. The electron capture detector was operated at $5-\mathrm{V}$ DC and was linear from $20 \mathrm{pg}$ to $2 \mathrm{ng}$ ABA. All samples were diluted to give $\mathrm{c}, \mathrm{t}-\mathrm{ABA}$ and $\mathrm{t}, \mathrm{t}-\mathrm{ABA}$ peaks within this range. The detection limit of the detector was $20 \mathrm{pg}$ of $\mathrm{c}, \mathrm{t}-\mathrm{ABA}$ giving a limit of detection of $2 \mathrm{ng} \mathrm{c}, \mathrm{t}$-ABA per sample. Recovery rates of $t, t-A B A$ averaged $80 \%$ and $90 \%$ for the free and bound extracts, respectively. The suspected ABA-methyl ester peak was identified by comparison of retention times of authentic $\mathrm{c}$, $\mathrm{t}$ ABA methyl ester and by its isomerization to $t, t-A B A$ methyl ester upon exposure to UV light (Lenton et al., 1971; Wood, 1983). Further irradiation with a stronger UV light resulted in the disappearance of both the c, t-ABA methyl ester peak and the $t, t-A B A$ methyl ester peak (Saunders, 1978). Peak purity was checked by GLC with a column of 3\% SP 2250 on 100/ 120 mesh supelcoport. This gave the same c, t-ABA methyl ester peak area relative to the internal standard. ABA was quantified by the relative peak area of the endogenous $\mathrm{c}, \mathrm{t}-\mathrm{ABA}$ and the intend standard (t, t-ABA) (Lenten et al., 1971; Saunders, 1978).

Trans, trans- $A B A$ used as an internal standard was separated from authentic mixed isomers of ABA (Sigma, St. Louis) by thin-layer chromatography (Wood, 1983). The purified $t, t-A B A$ was dissolved in methanol and stored in the dark at $4 \mathrm{C}$. The concentration of $\mathrm{t}, \mathrm{t}-\mathrm{ABA}$ in the internal standard stock solution was quantified by assuming equal detector response oft, $t-A B A$ methyl ester and c, t-ABA methyl ester (Saunders, 1978). The purity of the $t, t-A B A$ was checked by high pressure liquid chromatography (UV detection) and after methylation by GLC. The purified $\mathrm{t}, \mathrm{t}-\mathrm{ABA}$ internal standard contained $<0.1 \% \mathrm{c}, \mathrm{t}-\mathrm{ABA}$.

Plant samples prepared without added $t, t-A B A$ contained only trace concentrations of $t, t-A B A$, which is in agreement with Powell and Seeley (1974). One-microgram samples of mixed isomers of known relative concentrations were subjected to the entire purification procedure, and both isomers were recovered in equal proportions following methylation and GLC.

Water potential measurements. Diurnal measurements of $\psi_{\mathrm{w}}$ and $\psi_{\mathrm{s}}$ were made during a separate experiment with conditions identical to the first experiment except that 5 levels of PEGinduced water stress were used $\left(\psi_{\mathrm{PEG}}\right)$ [g PEG/liter]; - 0.25 $\mathrm{MPa}$ [105.5], -0.5 MPa [169.0], - 1.0 MPa [265.0], - 1.5 $\mathrm{MPa}$ [331.0], and - 2.0 MPa [386.5]. Water stress treatments were continued for 14 days or were terminated after 7 days with the plants returned to the control nutrient solution. $\psi_{\mathrm{w}}$ was measured with a pressure chamber and $\psi_{\mathrm{s}}$ was measured psychometrically from the expressed sap of frozen and thawed leaves
(Jones and Turner, 1978). All measurements were made on fully expanded midshoot leaves (LPI 10 to 15). Leaves were wrapped in a moist paper towel, detached, and immediately placed in a pressure chamber. Pressure was increased at a rate of 0.01 $\mathrm{MPa} \cdot \mathrm{s}^{-1}$ and the balance pressure was measured. After removal from the pressure chamber, leaves were rolled tightly and placed in vials made of tygon tubing and sealed with rubber stoppers. The sealed sample was frozen in liquid $\mathrm{N}_{2}$ and thawed on the bench to room temperature. The sample was placed in a vise, sap expressed, and sap osmotic potential measured with a Wescor C-52 sample chamber psychrometer (Jones and Turner, 1978). This measurement of $\psi_{\mathrm{s}}$ has been shown to be biased due to the dilution of cell sap with the apoplastic water fraction, which is essentially solute-free (Campbell et al., 1979; Jones and Turner, 1978). The true $\psi_{\mathrm{s}}$ is given by the equation $\psi_{\mathrm{s}}=\psi_{\mathrm{psy}} / 1-\mathrm{B}$, where B = apoplastic water content and $\psi_{\text {psy }}=$ osmotic potential of the mixed sap. The apoplastic water fraction was estimated by forcing $\left(\psi_{\mathrm{p}}\right)$ to 0 by pressurizing a leaf above the balance pressure until wilted as determined from pressure volume curves. When $\psi_{\mathrm{p}}=0$ the pressure bomb balance pressure is equal to $\psi_{\mathbf{s}}$ (Campbell et al., 1979). Measured values of apoplastic water fraction were 0.20 for the controls and -0.25 $\mathrm{MPa}$ treatments, 0.13 for the $-0.5 \mathrm{MPa}$ treatment and 0.065 for the more severe treatments. All measured $\psi_{\mathrm{s}}$ were corrected for apoplastic water fraction. $\psi_{\mathrm{p}}$ was calculated as the difference between $\psi_{\mathrm{w}}$ and $\psi_{\mathrm{s}}$. Diurnal curves for $\psi_{\mathrm{s}}$, and $\psi_{\mathrm{p}}$ showed relatively constant readings after the first $2 \mathrm{hr}$ of the photoperiod. Our reported midday values for $\psi_{w}, \psi_{s}$, and $\psi_{\mathrm{p}}$ were obtained by averaging the readings (three to six observations) over $12 \mathrm{hr}$ centered at the midpoint of the photoperiod.

The ABA experiment was a randomized complete block with each treatment replicated 12 times with six subsamples in each replicate, while the water relations experiment was a randomized complete block with eight replications. In both experiments, blocking was done on shoot length at the beginning of the stress treatment. A separate analysis of variance was performed at each observation date due to a significant treatment $\mathrm{x}$ date interaction in both experiments.

\section{Results}

\section{Abscisic acid experiment}

Growth. A PEG-induced water stress of -0.5 or $-1.0 \mathrm{MPa}$ resulted in a reduction in shoot growth rate (Fig. 2A), leaf expansion rate (Fig. 213), and new leaf emergence rate (Fig. 2C). By day 3, shoot growth rate was reduced $22 \%$ and $60 \%$ below the control treatment by water stresses of -0.5 and -1.0 $\mathrm{MPa} \psi_{\mathrm{PEG}}$, respectively. As the stress continued, shoot growth rate for the stressed plants continued to decline through day 17 , then leveled off through day 21. At the point of maximum reduction, shoot growth rates for the -0.5 and $-1.0 \mathrm{MPa} \psi_{\mathrm{PEG}}$ treatments averaged only $54 \%$ and $17 \%$ those of the controls, respectively. Following the date of treatment, the leaf expansion rate of the controls continued to increase while the shoot growth rate of the controls remained constant.

Calculation of average new internode length (the ratio of shoot growth rate to leaf emergence rate) showed no immediate reduction in average internode length due to water stress (Fig. 2D). Instead, average internode length for the stressed plants was close to that of the controls through day 10 . This stage was followed by a sharp reduction in internode length for the -1.0 $\mathrm{MPa} \psi_{\mathrm{PEG}} 1$ treatment for the remainder of the experiment. The 

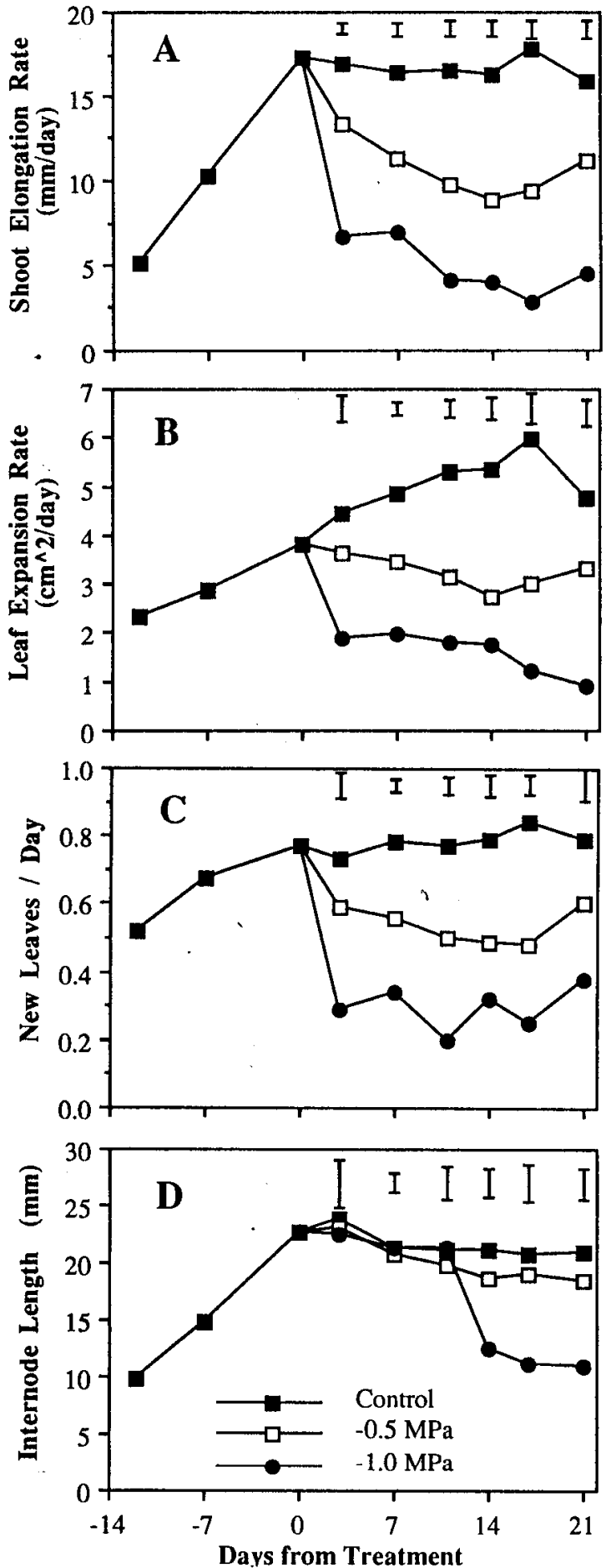

Fig. 2. Effect of moderate $(-0.5 \mathrm{MPa})$ and severe $(-1.0 \mathrm{MPa})$ PEG-induced water stress on shoot growth rate (A), leaf expansion rate $(B)$, new leaf emergence rate $(C)$, and average internode length (D) of apple seedlings over 21 days. $\psi_{\text {PEG }}$ indicates water potential of the PEG-modified nutrient solution. Vertical bars represent LSD at $P=0.05$ for each date $(\mathrm{n}=12)$.

lack of effect of water stress through day 10 resulted from the equal inhibition of elongation rate and leaf emergence rate, while the drop in average internode length at day 14 was caused by the continued decline in internode elongation rate after leaf emergence rate began a modest recovery.

Abscisic acid concentration. The endogenous concentration of free $\mathrm{ABA}$ in actively growing unstressed apple seedlings remained relatively static over the 4-week sampling period, but the concentration of ABA differed among sampled tissues (Table 1). When averaged over 4 weeks, the apical stem sections (the portion distal to LPI node 4) had the highest concentration of $\mathrm{ABA}$, followed by the immature leaves (leaves -1 to 4 ). The mature stem section (the portion between LPI nodes 8 and 12) ranked third while the mature leaves (leaves 9 to 12) had the lowest concentration among sampled tissues. The concentration of ABA in the apical stem sections exceeded that of the mature leaves by 10 -fold. The concentration of bound $\mathrm{ABA}$ was highest in the apical stem section, followed by the immature leaves. Both mature stems and leaves had similar low concentrations of bound ABA. The concentration of free ABA was more than 13-fold greater than the concentration of bound ABA for all tissues except mature leaves, where only a 4-fold difference existed.

The imposition of a PEG-induced water-stress of -0.5 or - 1.0 MPa resulted in a dramatic increase in free ABA concentration in all of the sampled tissues by the first sampling date, which was the midpoint of the first diurnal cycle after treatment (Fig. 3). In the apical stem section and immature leaves, the moderate stress of $-0.5 \mathrm{MPa} \psi_{\mathrm{PEG}}$ resulted in a 2fold increase and the more severe treatment of - 1.0 MPa $\psi_{\mathrm{PEG}}$ in an 8-fold increase in the concentration of free ABA relative to the control. In the mature stem section, the moderate stress also stimulated a 2 -fold increase in free ABA while the severe stress treatment increased to five times the concentration of the controls. In the mature leaves a 4- and 10-fold increase in free ABA resulted from the moderate and severe stresses, respectively. The relative differences between different tissues with each treatment remained fairly constant at day 1 ; however, in absolute terms the differences in free $\mathrm{ABA}$ concentration were magnified such that the concentration of free $\mathrm{ABA}$ in the apical stem section exceeded the mature leaves by $10,800 \mathrm{ng} \cdot \mathrm{g}^{-1} \mathrm{dry}$ weight in the $-1.0 \mathrm{MPa} \quad \psi_{\mathrm{PEG}}$ treatment.

The sharp increase in free ABA concentrations on day 1 after treatment was followed by a sharp drop by day 3 (Fig. 3). The free ABA concentration for both stress treatments was comparable to the control plants by day 3 in all tissues except mature leaves, where the concentrations remained significantly elevated until day 21. Continued stress resulted in relatively constant concentrations of free ABA. Significant differences in the concentration of free ABA were observed on days 7, 14, and 21, but the differences were small.

Water stress had a much less dramatic effect on the concentrations of bound ABA in the sampled tissue (Fig. 4). In the apical stem sections, a water stress of -0.5 and $-1.0 \mathrm{MPa}$

Table 1. Baseline endogenous concentrations of free and bound ABA in the stem and leaves of actively growing unstressed apple seedlings in a controlled environment averaged over 4 weeks.'

\begin{tabular}{lcc}
\hline \hline Plant tissue & $\begin{array}{c}\text { Free ABA } \\
\left(\mathrm{ng} \cdot \mathrm{g}^{-1} \text { dry }\right.\end{array}$ wt) & $\begin{array}{c}\text { Bound ABA } \\
\left(\mathrm{ng} \cdot \mathrm{g}^{-1} \mathrm{dry}\right.\end{array}$ \\
\hline $\begin{array}{l}\text { Apical stem section distal to LPI } \\
\quad \text { node 4 }\end{array}$ & $1390 \pm 53^{\mathrm{x}}$ & $92 \pm 5$ \\
$\begin{array}{l}\text { Mature stem section between LPI } \\
\quad \text { nodes } 8 \text { and 12 }\end{array}$ & $523 \pm 24$ & $32 \pm 2$ \\
$\begin{array}{l}\text { Immature leaves (LPI }-1 \text { to 4) } \\
\text { Mature leaves (LPI 9 to 12) }\end{array}$ & $854 \pm 39$ & $62 \pm 5$ \\
\hline
\end{tabular}

${ }^{2}$ Constant $27 \mathrm{C}$ and $50 \% \mathrm{RH}$ with $16-\mathrm{hr}$ photoperiod of $115 \mathrm{~W} \cdot \mathrm{m}^{-2}$ (400 to 700 rim).

'Node number based on plastochron index age of associated leaf. ${ }^{x}$ Mean $\pm \mathrm{SE}, \mathrm{n}=14$. 

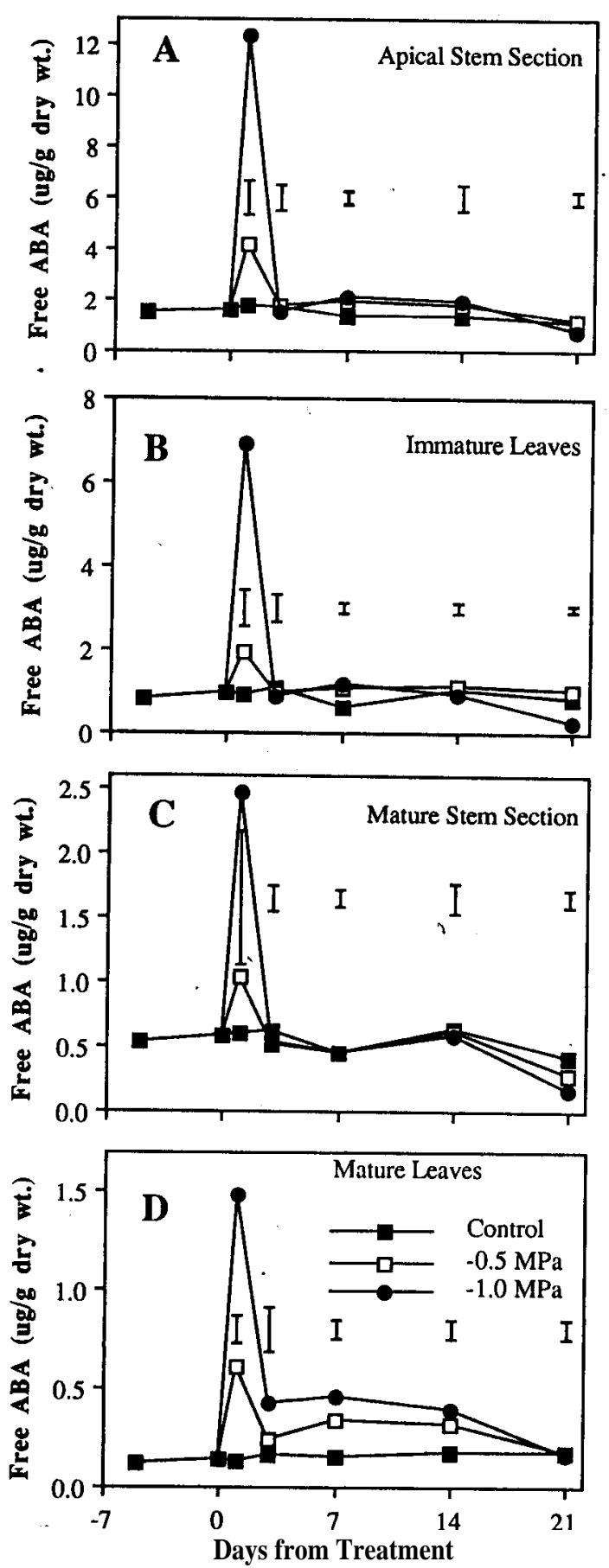

Fig. 3. Effect of moderate $(-0.5 \mathrm{MPa})$ and severe $(-1.0 \mathrm{MPa})$ PEG-induced water stress on free ABA concentrations in the apical stem section (A), immature leaves (B), mature stem. section (C), and mature leaves (D) of apple seedlings over 21 days. $\quad \psi_{\mathrm{PFF}}$ indicates water potential of the PEG-modified nutrient solution. Vertical bars represent LSD at $P=0.05$ for each date $(\mathrm{n}=2)$.

$\psi_{\mathrm{PEG}} \quad$ resulted in a 2 - and 3 -fold increase, respectively, in the concentration of bound $\mathrm{ABA}$ at day 1 followed by a slow decline to the concentration of the controls by day 7 . In the apical leaves and mature stem sections, water stress resulted in a small increase in bound ABA concentrations at days 1 and 3 after treatment but then returned to the concentration of the controls for the remainder of the experiment. In mature leaves, water stress resulted in a modest increase in bound ABA that persisted until the end of the experiment.
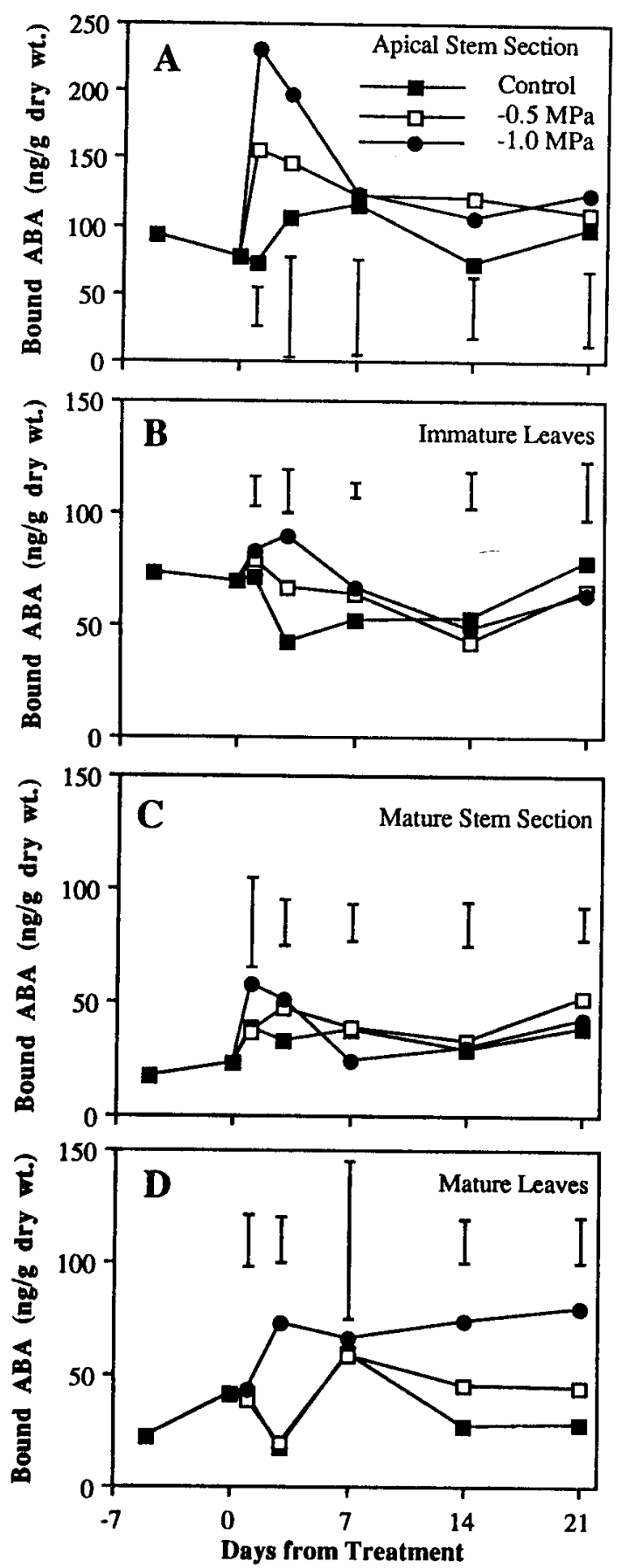

Fig. 4. Effect of moderate $(-0.5 \mathrm{MPa})$ and severe $(-1.0 \mathrm{MPa})$ PEG-induced water stress on bound ABA concentrations in the apical stem section (A), immature leaves (B), mature stem, section (C), and mature leaves (D) of apple seedlings over 21 days. $\quad \psi_{\text {pEG }}$ indicates water potential of the PEG-modified nutrient solution. Vertical bars represent LSD at $P=0.05$ for each date $(\mathrm{n}=2)$.

\section{Plant water relations experiment}

$\psi_{w}$ of unstressed plants was $-0.5 \mathrm{MPa}$ at predawn and dropped to $-1.0 \mathrm{MPa}$ at midday. Water stress resulted in a rapid reduction of midday $\psi_{\mathrm{w}}$ of mature leaves with a reduction to -2.6 $\mathrm{MPa}$ in the most severe treatment (Fig. 5A). The pronounced drop in $\psi_{w}$ on day 1 of the stress was followed by a gradual decline in $\psi_{w}$ for a few days followed by a moderate recovery by day 11 to a $\psi_{w}$ slightly higher than that of day $1 . \psi_{s}$ of unstressed plants was $-1.9 \mathrm{MPa}$ at predawn and dropped to 

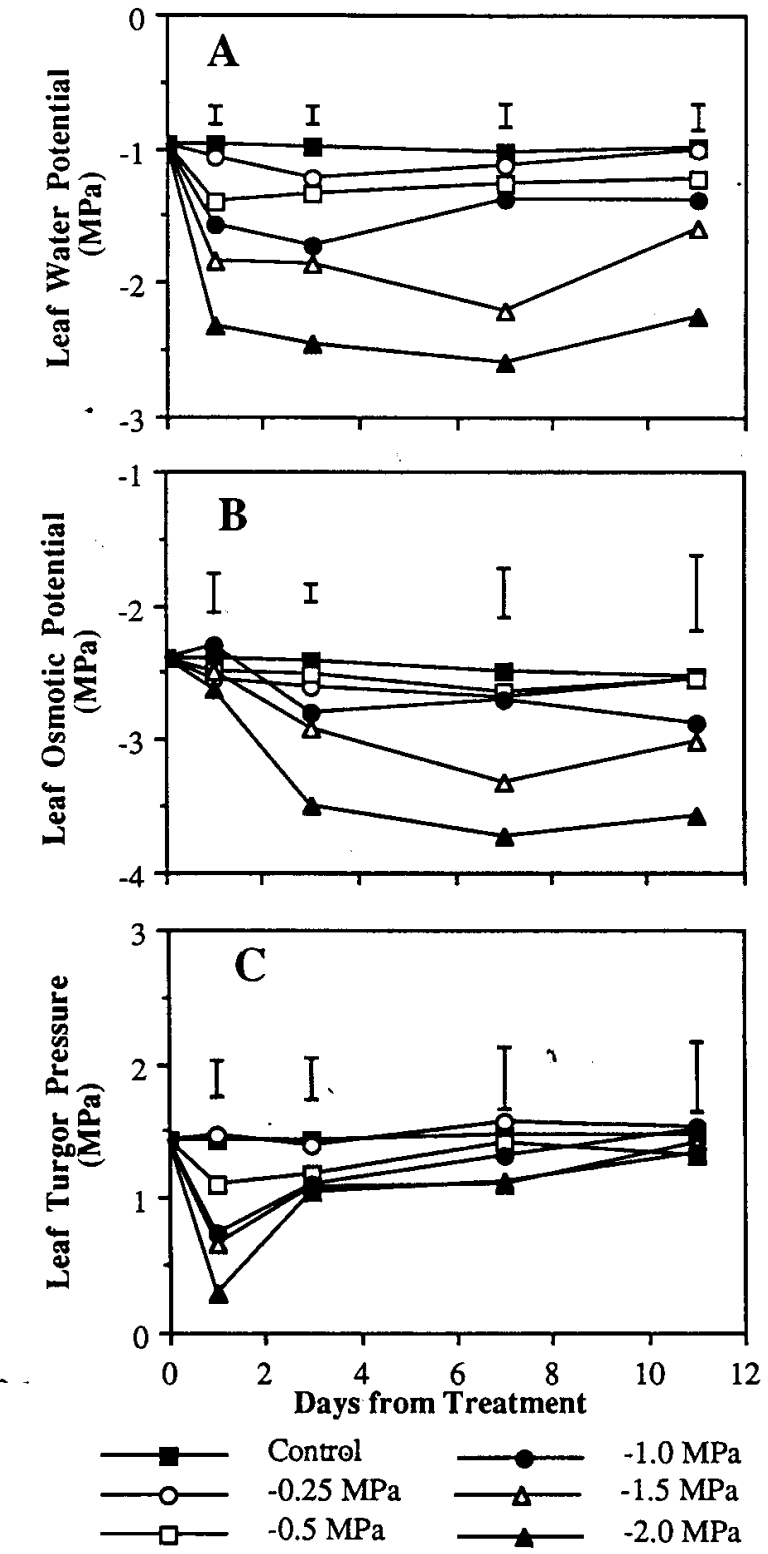

Fig. 5. Effect of PEG-induced water stress on midday, mature $\psi_{\mathrm{w}}$ (A); $\psi_{\mathrm{s}}$ (B); and $4 \quad$ (Cof apple seedlings. $\psi_{\text {PEG }}$ indicates water potential of the PEG-modified nutrient solution. Vertical bars represent LSD at $P=0.05$ for each date $(\mathrm{n}=4)$.

- 2.4 MPa at midday (Fig. 5B). Under a PEG-induced stress, midday $\psi_{\mathrm{s}}$ began to decrease progressively over a 7 -day period with a large portion of the decline occurring by day 3 . The initial decrease in $\psi_{\mathrm{s}} \mathrm{l}$ by day 1 was relatively modest. The calculated midday $\psi_{\mathrm{F}}$ was significantly reduced by water stress on day 1 with the most severe treatment reduced to $0.3 \mathrm{MPa}$ (Fig. 5C). Unstressed plants had an average $\quad \psi_{\mathrm{p}}$, of $1.4 \mathrm{MPa}$. By day $3, \psi$ had decreased sufficiently to allow a recovery in . $\psi_{\mathrm{p}}$. The recovery in $\psi_{\mathrm{p}}$ c continued until the end of the experiment with no significant differences due to treatment after day 3 .

The termination of stress after 7 days resulted in an immediate increase in midday $\psi_{\mathrm{w}}$ and a slower increase in $? \psi_{\mathrm{s}}$ spread over several days (data not presented). These increases resulted in high calculated $\psi_{\mathrm{p}}$ following a 7-day period of stress. These values exceeded the $\psi_{\mathrm{p}}$ of the controls by up to $0.8 \mathrm{MPa}$. The magnitude of the increase in turgor pressure following water stress paralleled the magnitude of the stress, with the most se- vere stress treatments resulting in the highest calculated turgor pressure following termination of the stress.

Evapotranspiration rate was reduced linearly due to the PEGinduced stress (Table 2). Transpiration rate remained inhibited for the entire 14-day water stress treatment with no recovery.

\section{Correlations}

Shoot growth rate was negatively correlated to ABA concentration in all sampled tissues on day 1 of the water stress treatment (Table 3). By day 3, growth rate was not correlated to ABA concentration in the growing tip or immature leaves but the concentration in the mature leaves remained correlated to growth rate. Over all 14 days of the water stress treatment, shoot growth rate was correlated to $\mathrm{ABA}$ concentration only in the mature leaves, but the correlation was relatively poor. $\psi_{w}$ was positively correlated to shoot growth rate for each date and over all dates. $\psi_{\text {: }} \quad$ was not correlated to shoot growth rate on day 1 , but by day 3 and at later dates it was highly correlated to growth rate, while $\psi_{\mathrm{p}}$ was highly correlated to growth rate over the first 7 days but by day 14 was not correlated. ABA concentration in the mature leaves was negatively correlated to $\psi_{w}$ of mature leaves on each date and over all dates of the study. ABA concentration was not correlated with $\psi_{\mathrm{s}}$ । of mature leaves on day 1 but was negatively correlated with ABA concentration on later dates. ABA concentration of the mature leaf was negatively correlated to $\psi_{\mathrm{p}} \quad$ on day 1 of the stress treatment but by day 14 no correlation existed. Pooling the data for all days during the water stress treatment showed shoot growth rate was positively correlated to $\psi_{\mathrm{p}}$ and $\psi_{\mathrm{s}} \mathrm{c}$ of mature leaves; ABA concentration of the mature leaf was negatively correlated to shoot growth rate; and ABA concentration was negatively correlated to $\psi_{w}$ and $\psi_{\mathrm{p}}$. The relationship of ABA and $\psi_{p}$ was quadratic (Fig. 6) but the curve was highly dependent on one data point; excluding this point resulted in a significant negative linear relationship between $\mathrm{ABA}$ and $\psi_{\mathrm{p}}$.

\section{Discussion}

The imposition of a PEG-induced water stress resulted in a rapid reduction in $\psi_{\mathrm{w}}$ that paralleled the severity of the stress. $\psi_{\mathrm{w}}$, however, does not indicate the effect of water stress on . $\psi_{\mathrm{p}}$ and cell expansion, and hence shoot growth (Hsiao, 1973; Jones et al., 1985; Powell and Thorpe, 1977; Turner and Jones, 1980). In our study, mid-shoot leaf $\quad \psi_{\mathrm{s}}$ ' was shown to adjust over three

Table 2. Evapotranspiration of apple seedlings grown in PEG-modified nutrient solution in a controlled environment.

\begin{tabular}{lrccc}
\hline \hline & \multicolumn{4}{c}{$\begin{array}{c}\text { Whole plant evapotranspiration rate } \\
\left(\mathrm{g} \cdot \mathrm{dm}^{-2} \cdot \text { day }^{-1}\right)^{\mathrm{y}}\end{array}$} \\
\cline { 2 - 5 } $\begin{array}{l}\text { Water potential of } \\
\text { PEG-modified nutrient }\end{array}$ & \multicolumn{4}{c}{ Days after treatment } \\
\cline { 2 - 5 } solution (MPa) & $0-3$ & $3-7$ & $7-10$ & $10-14$ \\
\hline-0.07 (Control) & 12.4 & 10.7 & 10.7 & 10.1 \\
-0.50 & 9.3 & 8.4 & 8.7 & 8.2 \\
-1.0 & 5.3 & 4.9 & 4.0 & 3.3 \\
LSD 0.05 & 1.1 & 1.8 & 2.8 & 2.3 \\
Regressions & & & $*$ & $* *$ \\
$\quad$ Linear & $* *$ & $* *$ & $* *$ & $*$ \\
Quadratic & NS & NS & $*$ & $*$ \\
\hline \hline
\end{tabular}

${ }^{2}$ Constant $27 \mathrm{C}$ and $50 \% \mathrm{RH}$ with $16-\mathrm{hr}$ photoperiod of $115 \mathrm{~W} \cdot \mathrm{m}^{-2}$ (400 to $700 \mathrm{rim}$ ).

'Evapotranspiration based on weight loss.

NS, ${ }^{*} * *$ Nonsignificant, or significant at $P=0.0 .5$ or 0.01 , respectively, $\mathrm{n}=18$. 


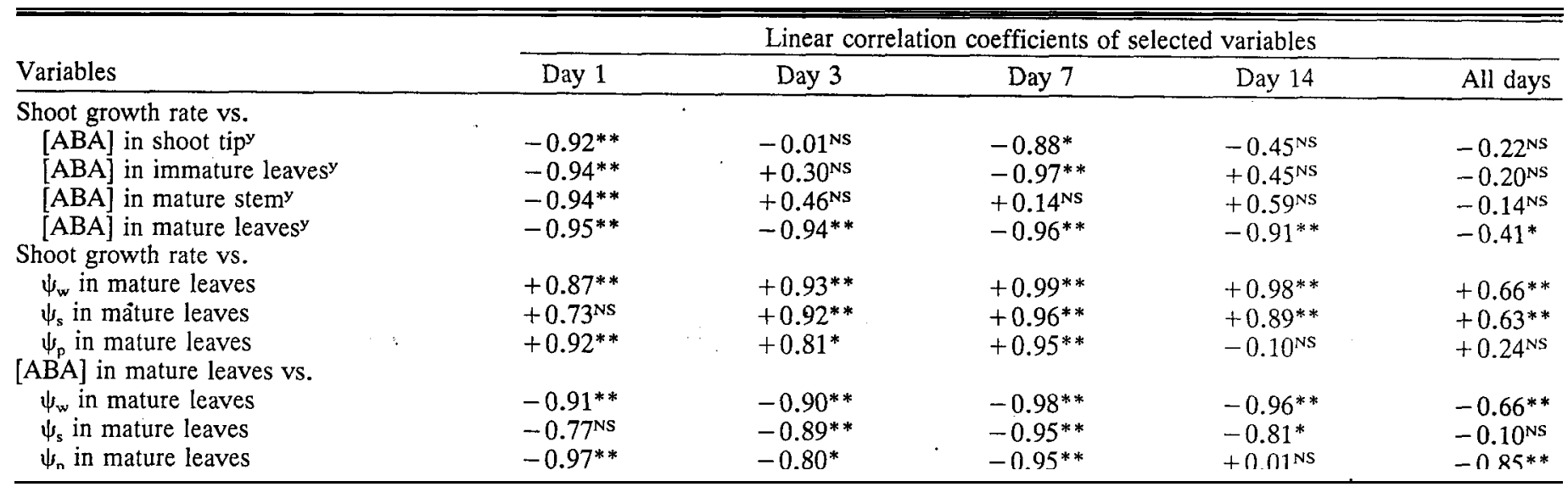

${ }^{2}$ Constant $27 \mathrm{C}$ and $50 \% \mathrm{RH}$ with $16-\mathrm{hr}$ photoperiod of $115 \mathrm{~W} \cdot \mathrm{m}^{-2}(400$ to $700 \mathrm{rim})$.

${ }^{y}$ Shoot tip $=$ section distal to LPI node 4 ; immature leaves $=$ LPI -1 to 4 ; mature stem $=$ section between LPI nodes 8 and 12 ; mature leaves = LPI 9 to 12 .

NS, ***Nonsignificant or significant at $\mathrm{P}=0.0 .5$ or 0.01 , respectively. $\mathrm{n}=6$ for individual days and $\mathrm{n}=24$ for all days.

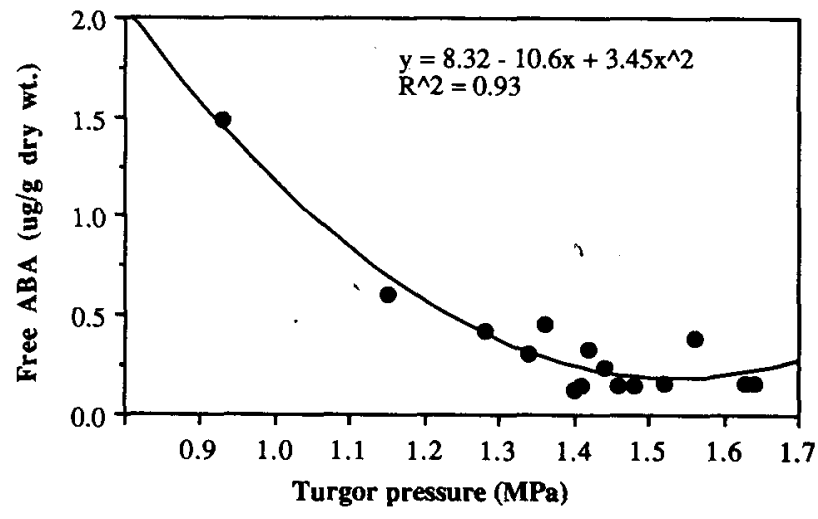

Fig. 6. Relationship of tree ABA concentration and $\psi_{\mathrm{p}}$ in mature leaves of apple seedlings during a 14-day PEG-induced water stress in a controlled environment.

days to allow a recovery in $\psi_{\mathrm{p}}$. The decrease in $\psi_{\mathrm{s}}$ due to water stress likely results from both passive concentration of solutes through tissue water loss and by active solute accumulation (Goode and Higgs, 1973; Jones and Turner, 1978; Lakso, 1983). The rapid imposition of the stress in our study is admittedly different than the gradual stress resulting from soil drying, but the rapid imposition of the PEG-induced water stress did not prevent the adjustment of $\psi_{\mathbf{s}}$ in our study. This result illustrates that apple trees can adjust quite rapidly to changing environments. Although soil generally dries slowly, rapid changes in water demand can occur through changes in atmospheric vapor pressure deficit.

The slower reduction in $\psi_{\mathrm{s}}$ than $\psi_{\mathrm{w}}$ led to a reduction of $\psi_{\mathrm{p}}$ on day 1 that paralleled the reduction in $\psi_{\text {PEG }}$. This reduction in leaf $\psi_{\mathrm{p}}$ can account for the initial reduction in shoot elongation rate and leaf expansion rate. The recovery in $\psi_{\mathrm{p}}$ by day 3 , however, was not accompanied by a recovery in shoot and leaf growth rates in the water stress treatments. Also, there was no correlation between shoot growth rate and turgor pressure of mature leaves over the entire 14-day stress period. This apparent anomaly can be resolved in light of reports that the expanding shoot tip and young leaves of apple show very little osmotic adjustment compared to mature leaves on the same plant (Lakso, 1984; Swietlik and Miller, 1983).
The PEG-induced rise in the concentration of free $c, t-A B A$ in the apical stem section, immature leaves, mature stem section, and mature leaves of apple seedlings is consistent with the reports of others (Bingham, 1972; Davies and Lakso, 1978). Our results show stress-induced ABA concentrations to be even higher in the shoot tip and immature leaves than in mature leaves. The rise in ABA concentration was rapid with a 5- to 10 -fold increase occurring during the first diurnal stress period. In red kidney bean, the maximum rate of biosynthesis of $\mathrm{ABA}$ occurred between 2.5 to $5 \mathrm{hr}$ after turgor was lost (Pierce and Raschke, 1981). Many investigators report a relationship of $\psi_{w}$ and ABA concentration with a threshold $\psi_{\mathrm{w}}$ required to stimulate ABA accumulation (Wright, 1978). It has been suggested that a decrease of $0.2 \mathrm{MPa}$ beyond the normal daytime $\psi_{\mathrm{w}}$ results in an accumulation of ABA. Bingham (1972) reported that as $\psi_{\mathrm{w}}$ of potted apple trees dropped from -0.4 to $-2.6 \mathrm{MPa}$, leaf ABA increased $=25$-fold. In our study, $\psi_{\mathrm{w}}$ in the -1.0 $\mathrm{MPa} \psi_{\mathrm{PEG}}$ treatment decreased to $-1.7 \mathrm{MPa}$ while leaf ABA concentration increased 10-fold; however, the baseline concentrations of ABA were nearly 10-fold greater than those reported by Bingham (1972).

The decline in ABA concentrations by day 3 after treatment to the level of the controls was unexpected. In other species, ABA concentrations remained elevated until the stress was relieved (Turner and Jones, 1980; Wright, 1978). The rapid decline in ABA concentrations while the stress continued may be explained if cell turgor pressure is the controlling factor in ABA synthesis under stress conditions. Davies and Lakso (1978) reported that ABA concentrations in mature leaves of apple seedlings appear to correlate better with $\psi_{\mathrm{p}}$ than with: $\psi_{\mathrm{w}}$. . Pierce and Raschke (1981) reported that when stressed red kidney bean leaves were dehydrated to different degrees, there-establishment of the slightest positive turgor was sufficient to result in the maximum stimulation of metabolism of ABA to phasaeic acid. In our study, the rise and decline in free ABA concentrations of all sampled tissues paralleled the changes in mature : $\psi_{\mathrm{p}}$ and not the changes in $\psi_{\mathrm{w}}$. Over the entire 14-day stress treatment, ABA concentration in the mature leaf was better correlated to $\psi_{\mathrm{p}}$ than $\psi_{\mathrm{w}}$ ( (Table 3). These results support the concept of the dependence of mature leaf ABA concentration on $\psi_{\mathrm{p}}$. If the quadratic relationship of ABA concentration and $\psi_{\mathrm{p}}$ presented 
in Fig. 6 is correct, then substantial ABA is not accumulated in the leaf until turgor drops below 1.3 $\mathrm{MPa}$.

The increase in free ABA due to water stress without a similar decrease in bound ABA supports the concept of de novo synthesis rather than a release of bound ABA. Hogue et al. (1983) with scotch pine and Pierce and Raschke (1981) with red kidney bean have reported that the increase in free ABA due to water stress results from a stimulation of $\mathrm{ABA}$ synthesis rather than from a release of conjugated $\mathrm{ABA}$ or an inhibition of metabolism. They report an increase in bound $\mathrm{ABA}$ and $\mathrm{ABA}$ metabolizes due to water stress. The decrease in free ABA by day 3 in our study was not associated with an increase in bound ABA in any tissue, which indicates ABA was metabolized (probably to phasaeic acid) and not conjugated. The low concentration of bound $\mathrm{ABA}$ in the actively growing shoots argues against bound ABA serving as a storage form of ABA.

Although baseline ABA concentrations were highest in the apical stem section and lowest in the mature leaves, the site of ABA biosynthesis in the plant is reported to be the mature leaves with probable localization in the chloroplasts (Walton, 1980; Wright, 1978). It is also possible that ABA could be synthesized or stored in the root and translocated to the shoot during periods of stress (Zhang et al., 1987). Hoad (1978) has shown that ABA is actively transported out of mature leaves in the phloem and transported to stem apices, seeds, and fruits. The results of our study support this concept in two ways: 1) the higher baseline ABA concentrations in the mature stems than in mature leaves are consistent with the concept of an active accumulation of ABA at the phloem-loading step in the leaf (Hoad, 1978); and 2) in stressed plants, the ABA concentration in the immature leaves also declined by day 3 even though these leaves have been shown to have very little osmotic adjustment (Lakso, 1983) and hence recovery in turgor pressure.

ABA is also known to cause stomatal closure. Although stomatal conductance was not measured in our study, estimates of whole plant evapotranspiration rate showed a decrease due to water stress that paralleled the increase in ABA concentrations. However, the drop in ABA concentrations by day 3 was not associated with any increase in transpiration. It maybe that the lack of recovery in transpiration could be due to stomata becoming sensitized to internal $\mathrm{CO}_{2}$ concentration, which keeps stomates closed (Raschke, 1979).

On the basis of our data, ABA does not appear to play a central regulatory role in shoot growth. Although the initial rise in free ABA concentrations in the growing leaves and stems due to water stress paralleled the reduction in shoot growth rate and leaf expansion rate, the rapid decline in ABA concentration in these tissues by day 3 was not associated with any recovery in growth rate. In fact, growth rate of the two stress treatments continued to decline over the next 2 weeks, while ABA concentrations remained low. This continued inhibition of growth is more likely the result of lack of turgor in the young leaves and shoot apex (Lakso, 1983) than to ABA concentration. The case for ABA playing a central regulatory role in shoot growth is further weakened by the distribution of $\mathrm{ABA}$ in the plant. The greatest concentration of ABA in apple trees is found in the shoot tip and young leaves, with lower concentrations in mature leaves and stems (Table 1). However, Powell (1975) has suggested that the effect of ABA on shoot growth depends on the balance of other hormones in the growing shoot and leaves.

In the case of water stress, the rapid response of ABA likely serves as a mechanism to prevent desiccation and probably overrides other biochemical growth promoters. A similar case was reported by Hoad and Monselise (1976) who sprayed M.26 apple rootstock with succinic acid 2,2-dimethylhydrazide that reduced shoot growth and led to a rapid build-up of ABA in the shoot tip, followed by a reduction in the concentration of gibberellic acid-like substances.

\section{Literature Cited}

Avery, G. S., Jr., P.R. Burkholder, and H.B. Creighton. 1937. Production and distribution of growth hormone in Aesculus and Malus and its probable role in stimulating cambial activity. Amer. J. Bet. 24:51-58.

Bingham, G.E. 1972. Stomatal response in field corn (Zea mays L.) and apple (Malus sylvestris). $\mathrm{PhD}$ Thesis, Cornell Univ., Ithaca, N.Y.

Black, T.H. 1983. The preparation and reactions of diazomethane. Aldrichimica Acts 16(1):3-10.

Campbell, G. S., R.I. Papendick, E. Rabie, and A.J. Shayo-Ngowi. 1979. A comparison of osmotic potential, elastic modulus and apoplastic water in leaves of dryland winter wheat. Agron. J. 71:3136.

Davies, F.S. and A.N. Lakso. 1978. Water relations in apple seedlings: changes in water potential components, abscisic acid levels and stomatal conductance under irrigated and non-irrigated conditions. J. Amer. Soc. Hort. Sci. 103:310-313.

Gergeley, I., R.F. Korcak, and M. Faust. 1980. Polyethylene glycol induced water stress effects on apple seedlings. I. Methodology, water consumption, and dry matter production. J. Amer. Soc. Hort. Sci. 105:854-857.

Goode, J.E. and K.H. Higgs. 1973. Water, osmotic and pressure potential relationships in apple leaves. J. Hort. Sci. 48:203-215.

Hoad, G.V. 1978. Effect of water stress on abscisic acid levels in white lupin (Lupinus albus L.) fruit, leaves and phloem exudate. Planta 142:287-290.

Hoad, G.V. and S.P. Monselise. 1976. Effects of succinic acid 2,2dimethylhydrazide (SADH) on the gibberellin and abscisic acid levels in stem tips of M.26 apple rootstock. Sci. Hort. 4:41-47.

Hoagland, D.R. and D.I. Arnon. 1950. The water-culture method of growing plants without soil. Calif. Agr. Expt. Sta. Cir. 347.

Hogue, E., W. Dathe, M. Tesche, and G. Sembdner. 1983. Abscisicacid and its beta-D gluco pyranosyl ester in saplings of scotch pine Pinus sylvestris in relation to water stress. Biochem. Physiol. Pflanz. 178:287-295.

Hsiao, T.C. 1973. Plant responses to water stress. Ann. Rev. Plant Physiol. 24:519-570.

Jones, H. G., A.N. Lakso, and J.P. Syvertsen. 1985. Physiological control of water status in temperature and subtropical fruit trees. Hort. Rev. 7:301-344.

Jones, M.M. and N.C. Turner. 1978. Osmotic adjustment in leaves of sorghum in response to water deficits. Plant Physiol. 61: 122-1 26.

Lakso, A.N. 1983. Morphological and physiological adaptations for maintaining photosynthesis under water stress in apple trees, p. 8593. In: R. Marcelle, H. Clijsters, and M. van Poucke (eds.). Effects of stress on photosynthesis. Nijhoff/Junk, The Hague, Netherlands.

Lakso, A.N. 1984. Seasonal osmotic relations in apple leaves of different ages . J. Amer. Soc. Hort. Sci. 109:544-547.

Lenton, J. R., V.M. Perry, and P.F. Saunders. 1971. The identification and quantitative analysis of abscisic acid in plant extracts by gasliquid chromatography. Planta, 96:271-280.

Lewis, R.W. and S.N. Visscher. 1982. A simplified purification method for the analysis of abscisic acid. Plant Growth Regulation 1:25-30.

Little, C.H.A. and P.F. Wareing. 1981. Control of cambial activity and dormancy of Picea sitchensis by indol-3-ylacetic and abscisic acids. Can. J. Bet. 59:1480-1493.

Looney, N. E., J.S. Taylor, and R.P. Pharis. 1988. Relationship of endogenous gibberellin and cytokinin levels in shoot tips to apical form in four strains of 'McIntosh' apple. J. Amer. Soc. Hort. Sci. 113:395-398. 
LuckWill, L.C. and P. Whyte. 1968. Hormones in the xylem sap of apple trees. S.C.I. Monogr. 31:87-101.

Maksymowych, R. 1973. Analysis of leaf development, p. 1-35. In: M. Abercrombie et al. (eds). Developmental and cell biology series. Cambridge University Press, Cambridge.

Mousdale, D.M.A. and M. Knee. 1979. Poly-N-vinylpyrrolidone column chromatography of plant hormones with methanol as an eluent. J. Chromatography 177:398-400.

Pierce, M. and K. Raschke. 1981. Synthesis and metabolism of abscisic acid in detached leaves of Phaseolus vulgaris L. after loss and recovery of turgor. Planta 153:156-165.

Powell, D.B.B. and M.R. Thorpe. 1977. Dynamic aspects of plantwater relations, p. 259-285. In: J.J. Landsberg and C.V. Cutting (eds.). Environmental effects on crop physiology. Academic Press, London.

Powell, L.E. 1975. Some abscisic acid relationships in apple. Rivista Ortoflorofruit. Italiana 59:424-432.

Powell, L.E. and S.D. Seeley. 1974. The metabolism of abscisic acid to water soluble complex in apple. J. Amer. Soc. Hort. Sci. 99:439441.

Raschke, K. 1979. Movements of stomata. Encyclopedia of plant physiology. New Series 7:381-441.

Sandke, G. 1982. Dynamics of the abscisic acid content in terminal buds of short shoots of 'Golden Delicious' during the vegetation period and its effect on bud formation. Arch. Gartenbau 30:263273.

Saunders, P.F. 1978. The identification and quantitative analysis of abscisic acid in plant extracts, p. 115-134. In: J.R. Hillman (cd.). Isolation of plant growth substances. Cambridge University Press, Cambridge.

Seeley, S.D. and L.E. Powell, Jr. 1981. Seasonal changes of free and hydrolyzable abscisic acid in vegetative apple buds. J. Amer. Sot. Hort. Sci. 106:405-409.

Steuter, A. A., A. Mozafar, and J.R. Goodin. 1981. Water potential of aqueous polyethylene glycol. Plant Physiol. 67:64-67.

Swietlik, D. and S.S. Miller. 1983. The effects of paclobutrazol on growth and response to water stress of apple seedlings. J. Amer. Soc. Hort. Sci. 108:1076-1080.

Turner, N.C. and M.M. Jones. 1980. Turgor maintenance by osmotic adjustment: a review and evaluation, p. 87-103. In: N.C. Turner, and P.J. Kramer (eds.). Adaptation of plants to water and high temperature stress. Wiley-Interscience, New York.

Walton, D.C. 1980. Biochemistry and physiology of abscisic acid. Annu. Rev. Plant Physiol. 31:453-489.

Wood, B. W.. 1983. Changes in indoleacetic acid, abscisic acid, gibberellins, and cytokinins during budbreak in pecan. J. Amer. Soc. Hort. Sci. 108:333-338.

Wright, S.T.C. 1978. Phytohormones and stress phenomena, p. 495536. In: D.S. Letham, P.B. Goodwin, and T.G.V. Higgins (eds.). Phytohormones and related compounds-a comprehensive treatise. vol. II. Elsevier, Amsterdam.

Zhang, J., U. Schurr, and W.J. Davies. 1987. Control of stomatal behaviour by abscisic acid which apparently originates in the roots. J. Expt. Bet. 38:1174-1189. 